\title{
INTEGRACIÓN DE LA ÉTICA EN LA TOMA DE DECISIONES UN ENSAYO DESDE UNA PERSPECTIVA EPISTEMOLÓGICA Y ANTROPOLÓGICA A PARTIR DEL MODELO DE PÉREZ LÓPEZ
}

\author{
INTEGRATION OF ETHICS IN DECISION MAKING \\ AN ESSAY FROM AN EPISTEMOLOGICAL PERSPECTIVE \\ FROM THE PEREZ MODEL
}

Mag. Gonzalo Flores-Castro Lingán

Docente

Seminario Arquidiocesano "San Jerónimo" / Arequipa-Perú

e-mail: gonzalofcl_1@hotmail.com

\section{Resumen}

En este trabajo se exponen algunas de las razones por las que los modelos de toma de decisiones en las organizaciones no consideran en ellos, criterios éticos, en especial por los criterios del homo economicus y el positivismo. Se intenta resolver el problema mediante el supuesto de la unidad de la acción humana, tomando como modelo la teoría de la acción de Pérez López. Se exponen algunos fundamentos filosóficos necesarios para generar un modelo de toma de decisiones y se presenta la teoría de Pérez López haciendo énfasis en las razones epistemológicas y antropológicas que se tienen para su uso; en especial, el hecho de ser un modelo completo de la acción y no una abstracción incompleta.

Palabras Clave: Ética, economía, toma de decisiones, acción humana, antropología filosófica, antropología analítica, epistemología, teoría de la acción.

\section{Abstract}

This paper exposes some of the reasons why decision-making models in organizations do not consider ethical criteria in their models, especially because of the homo economicus and positivism assumptions. We try to solve the problem through the assumption of the 
unity of human action, taking Pérez López's theory of action as a model. Some necessary philosophical assumptions are exposed to generate a model of decision making. We expose the theory of Pérez López emphasizing the epistemological and anthropological reasons for its use; especially, the fact of being a complete model of the action and not an incomplete abstraction.

Key Words: Ethics, economy, decision making, human action, philosophical anthropology, analytical anthropology, epistemology, action theory.

\section{Introducción}

A finales de la primera década del siglo XXI una lamentable crisis económica afligió a muchas personas alrededor del mundo. Si bien sus causas fueron variadas y complejas (Cfr. Andreu y Rosanas, 2011); podemos afirmar que, además de una crisis de dirección

o management ${ }^{1}$ (una falla de la conducta ética de las personas que estaban al frente de las organizaciones), fallaron los modelos teóricos y prácticos en los que se inspiraban, porque sus fundamentos antropológicos y éticos eran incorrectos (Argandoña, 2010a). Esto no es algo nuevo de señalar, pues desde los inicios de los estudios en dirección de empresas, resulta evidente que la entera actividad económica está vinculada a una visión concreta del ser humano ${ }^{2}$ (Melé y González Cantón, 2015: 20); y que, por tanto, de ser errónea dicha visión puede

1 La actividad directiva recibe varios nombres: gerencia, administración, management, gobierno, gestión, etc. Esto puede ser síntoma de varios paradigmas subyacentes que pretendemos desvelar en cierta medida. Por ello, en esta investigación, tomamos las distintas denominaciones del management indistintamente (Cfr. Alcázar 2015: 116)

2 Sobre los diferentes problemas que presenta la antropología -y la filosofía- detrás de las teorías del management al uso se puede consultar a Melé \& González Cantón (2015). traer consecuencias graves en la praxis real 3 . Así pues, si la visión del hombre que tienen las teorías del management al uso no integra la parte moral del ser humano, los modelos teóricos que se construyan a partir de ella no contemplarán dichos criterios, a pesar de la buena voluntad de quienes toman decisiones.

¿Por qué ocurre esto? Nuevamente, las razones son varias y complejas. Una de las ellas es el generalizado uso del modelo -muchas veces implícito ${ }^{4}$ - de homo economicus en

3

Esto es algo que se viene investigando. Por ejemplo, ya en 1998 Ghoshal y Caulkin, dos prestigiosos investigadores de dirección de empresas, advirtieron que había un vacío filosófico en su disciplina (Melé y González Cantón 2015: 21). Por su parte, Ian I. Mitroff, disinguished professsor de Política de Empresa de la Marchall School of Business, advertía que «las bases filosóficas del mundo empresarial deben ser revisadas en sus fundamentos» (2004: 187).

4 Sobre lo implícito de los supuestos, diría el economista Keynes: «Las ideas de los economistas y los filósofos políticos, tanto cuando 
varias de las teorías del management, cosa que ya advirtieran diversos autores (Cfr. Ghoshal, 2005; Rosanas, 2009; Andreu \& Rosanas, 2011)5. Otra de las razones está en asumir, a veces inadvertidamente, un paradigma positivista tanto en la ciencia económica como en las ciencias sociales en general $^{6}$. Esto último es algo que muchos autores han tomado como supuesto explícito de sus teorías, siendo el ejemplo más claro el de Herbert Simon, quien afirmaría en Administrative Behavior (1997: 55) que «(...) como punto de partida, aceptaremos

aciertan como cuando yerran, son mucho más poderosas que lo que comúnmente se piensa (...) los hombres de acción, que se creen muy al margen de cualquier influencia intelectual, son esclavos de algún economista difunto (...) sus ideas son peligrosas para bien o para mal», citado por Alcázar (2015: 115-116).

«Mainstream economics has, in the main, always worked on the assumption of Homo Economicus (...)» (Ghoshal, 2005: 85); «El consenso actual más generalizado [del estado del management] se basa en el predominio de la ciencia económica, de sus supuestos y de sus métodos. (...) El economicismo reinante ha puesto un gran énfasis en las variables económicas del "negocio" (con frecuencia, con exclusión de cualesquiera otras) (...)» (J. M. Rosanas, 2009: 22); «El acento [del management] en la eficacia inmediata en términos de resultados financieros (...) como único fin, dibuja un concepto pesimista de un ser humano que solo reacciona a estímulos económicos, [olvidando] otras dimensiones fundamentales (...)» (Andreu y Rosanas, 2011: 1-2), en todas las citas los corchetes son nuestros.

Este hecho -afirma Melé \& González Cantón (2015: 20)- puede atribuirse al prestigio social de la ciencia, así como a la introducción generalizada de las ciencias sociales en los estudios de dirección a partir de la década de 1950. las conclusiones alcanzadas por una escuela concreta de pensamiento filosófico -el positivismo lógico- (...)»7. En ambos casos, existe una serie de problemas que no permiten la integración del actuar ético del ser humano.

¿Qué implica el homo economicus? Este supuesto antropológico (sea en su versión clásica, neoclásica o en la versión de la economía austriaca ${ }^{8}$ ) tiene el riesgo de crear una mentalidad racional, exclusivamente entendida como calculadora, egoísta y amoral; hecho que se ve confirmado por distintos estudios que muestran que los estudiantes de ciencias económicas y empresariales tienden a ser más egoístas que los alumnos de otras disciplinas (Melé y González Cantón, 2015: 21-22). Así, «si el homo economicus es esencialmente egoísta, la ética es superflua» (Melé y González Cantón 2015: 46) ${ }^{9}$.

Simón, al escribirsu autobiografía-en 1991- se refiere a la postura filosófica que eligió desde su época de estudiante universitario en Chicago en estos términos: «yo ya había adoptado un Positivismo lógico que nunca he abandonado (ahora preferiría llamarlo empirismo» citado por González (2003: 12). Al respecto dice Pérez López (1991: 20): «Posiblemente la elección de Herbert Simon no fue demasiadoafortunada. Difícilmente podría encontrarse una postura metodológica menos fecunda para un análisis riguroso de la acción humana que aquella que se deriva del dogmatismo "a priori” del positivismo lógico».

«La Escuela Austríaca de economía forma parte de la tradición heterodoxa de la economía. (... ) Esta escuela acepta la idea del homo economicus, aunque con diferencias significativas a la versión neoclásica» (Meléy González Cantón, 2015:39). Podemos añadir como crítica que, si bien el modelo del homo economicus ha demostrado, en algunos casos, ser eficaz para describir e incluso predecir la conducta económica humana; su 
¿Qué implica un paradigma positivista? Este supuesto epistemológico sustituye la realidad por abstracciones matematizables, considerando aquellos aspectos que son susceptibles de predicción y control (Feser, 2014: 13). Este tipo de metodología no tiene problema en el caso de ciencias naturales, pero resulta ser un reduccionismo cuando es aplicado a realidades humanas ${ }^{10}$. Esto se debe a que las mediciones empíricas no acceden a juicios de valor sobre el bien o el mal y porque, por otra parte, la economía positiva y normativa separa el ser del deber ser (falacia naturalista), en donde no puede derivarse el deber ser (las recomendaciones éticas) del ser (aquel suceso

valor predictivo ha resultado más débil de lo que muchos aseguraban (Pierpaolo y Archer, 2015: 68-69) (Archer, 2005: 36-56).

10

La metodología positivista puede ser aún más peligrosa de lo que se piensa. Consideremos el siguiente ejemplo: «[Sigamos] un problema corriente en los manuales de Física y de ciencias naturales: "Un elefante se desliza por una pendiente herbosa”. El estudiante avisado sabe que no es necesario ocuparse demasiado de esto; está puesto allí solo para dar la impresión de realismo. Lee más adelante: "La masa del elefante es de dos toneladas”. Ahora se comienza a hablar seriamente: el elefante desaparece del problema y lo sustituye una masa de dos toneladas. ¿Qué cosa son esas dos toneladas, verdadero sujeto del problema? Se refiere a una propiedad que descubrimos vagamente como "peso" y se manifiesta en una región particular del mundo externo... No importa a qué cosa se refieren "dos toneladas"; ¿qué cosa son? ¿Cómo han entrado realmente en nuestra experiencia en modo tan preciso?» (Genta, 2009: 12); como resulta evidente, un elefante no se reduce a su peso, a su tamaño, etc., de la misma forma que una persona no se reduce a lo que podamos saber de ella a partir de las mediciones empíricas, pues es un yo inescrutable e irrepetible. económico que ocurre en cada momento) (Argandoña, 1989).

Tomando en cuenta solamente estos dos fundamentos filosóficos de las teorías del management, podemos decirquetodo modelo construido en base a dichas premisas inevitablemente excluirá a priori variables que permitan tomar en cuenta la moralidad de la acción humana como criterio dentro del mismo modelo. Esta es la famosa "tesis de la separación”, que pone por un lado las decisiones económicas y por otro las decisiones éticas. Esta escisión de la decisión merece ser analizada, pues es una manera de entender la acción humana que no corresponde a la realidad. Subyace a esta interpretación de la acción humana una manera de entender la acción misma: por un lado están las acciones éticas y por otro las económicas, que son supuestamente amorales. Olvidan, sin embargo, que -como hace notar Argandoña (2010b: 8-11)- «no hay (...) decisiones puramente económicas, porquetodas afectan a las diversas motivaciones de las personas y, por tanto, a sus aprendizajes: todas las decisiones serán económicas, pero también éticas y sociológicas» (cursivas nuestras).

La acción humana es una sola. Uno no actúa simultáneamente, es decir, no hace dos acciones simultáneas, sino que realiza una sola acción con distintas consecuencias para la empresa, para el Estado, para la familia, o para el propio decisor. Pero la acción es única, los otros puntos de vista son abstracciones incompletas ${ }^{11}$. Es decir, desde el punto devista

11

Término que utiliza Pérez López para referirse a modelos que no consideren todos los aspectos que, como mínimo, deben considerarse en la toma de decisiones. 
abstracto podemos decir «seanaliza la acción humana desde el punto de vista de sus resultados económicos, suponiendo ceteris paribus, entonces...»; sin embargo, en la realidad, las cosas no son iguales, e incluyen todas las variables al mismo tiempo (económicas y morales). De esa forma, los supuestos subyacentes que separan los resultados éticos de las acciones de los resultados económicos (homo economicus o positivismo), son incapaces de sustentar un modelo que integre algo que en la realidad es una sola cosa. Como dice Tomás de Aquino, parafraseando a Aristóteles, «un pequeño error en el inicio es un gran error en el final» (Feser, 2010: vii).

En este ensayo pretendemos unificar aquello que los supuestos epistemológicos y antropológicos del positivismo y el homo economicus han escindido (la ética de la toma de decisiones empresarial) a través de un modelo que unifique estos aspectos desde la unidad de la acción humana. Para ello, haremos uso del modelo del profesor Juan Antonio Pérez López (1991). No deseamos exponer todo el modelo perezlopiano, trabajo que han llevado otros a cabo (Cfr. Ariño 2005; Chinchilla y Moragas, 2007; Alcázar García 2010 \& Ferreiro y Alcázar, 2012), sino algunas razones antropológicas ${ }^{12}$ y epistemológicas que permitan vislumbrar en el modelo de Pérez López una solución para integrar la ética en la toma de decisiones.

\section{Algunos presupuestos filosóficos}

Antes de empezar, deseamos hacer explícitos algunos de los supuestos en los que nos basaremos, afrontando en primer lugar la dificultad que tienen las ciencias del hombre. El primer problema que se presentaal plantear

De las cuales se derivan las razones éticas. un modelo científico es la posibilidad de hacer ciencia del hombre; es decir, si somos capaces de crear un modelo que tome en cuenta lo esencial del hombre (integre todos sus aspectos) y pueda servir de herramienta a la hora de tomar decisiones. Las razones de este problema son varias ${ }^{13}$, aquí solo consideraremos una: el ser persona.

El hecho de ser persona implica la imposibilidad degeneralización. «Esa realidad concreta quellamamos persona -dice Pérez López (1991: 50) -es tan única e irrepetible que sería vano todo intento de generalización $»^{14}$. Si cada ser humano es persona, es decir, es único e irrepetible; entonces es en vano todo intento de hacer ciencia, pues todo modeloutilizado tiene como requisito la universalidad -la capacidad de utilizar modelos para todos o la mayoría de casos- (Sanguineti, 2007: 170). Este problema surge debido la existencia de una realidad espiritual en el ser humano, una que aún no hemos terminado de conocer y que hace que cada una sea irrepetible. Esto se ve reflejado en el famoso problema mente-cerebro, el cual presenta diversas interpretaciones (Feser, 2006). Al parecer, existe una realidad que, o bien no es reducible a lo material, o bien nuestros instrumentosy métodos paraanalizar la realidad material son insuficientes para dar cuenta de lo que la mente es (Nagel, 2012). Si esto es así, cada persona es inescrutable y es imposible una generalización.

13 Se pueden revisar una serie de problemas que surgen a la hora de hacer ciencias humanas en Artigas (2009, 188-193).

14 Como dice Leonardo Polo: «Como cada persona es distinta, no hay dos modos iguales de mandar y tampoco de obedecer» (citado por Alcázar, 2015: 166). 
Ahora bien, esto haría imposible la ciencia humana, pero no es así. Podemos estudiar al hombre en lo que es su naturaleza o modo de ser, pero noagotar nuestro conocimiento deél en lo que respecta a su persona ${ }^{15}$. Todos somos hombres y somos personas; somos personas en tanto que únicos e irrepetibles (cada quien es cada quien), y somos muy similares en tanto que naturaleza o modo de ser. Por tanto, podemos aventurar un modelo mínimo que tome en cuenta la naturaleza humana. Sin embargo, hay que recalcar que, para tomar decisiones donde personas (incluido el decisor) estén involucradas, se debe tener siempre presente lo siguiente: (a) saber quién es uno mismo como persona distintay quiénes son los demás (es decir, ir conociendoa cada quien en su radical novedad), y (b) conocer cómo es la naturaleza humana común de los hombres, y cómo se activa su perfeccionamiento (Alcázar, 2015: 168).

Tomaremos en cuenta una serie de supuestos filosóficos sobre la naturaleza humana (o modo de ser humano) que pueden ser encontradas en distintas tradiciones filosóficas y que creemos pueden ser aceptadas por un número amplio de personas. De esta forma, se podrá exponer el modelo perezlopiano haciendo explícito lo implícito en otros modelos de toma de decisiones. Los supuestos son los siguientes: (a) La acción humana es una, pues es una y la misma persona la que realiza distintas acciones; si bien puede ser que la acción tenga una intención económica y sea analizable desde ese punto de vista abstracto, al realizarla el agente decisor, esta

15 Teniendo en cuenta que la distinción, aunque real, no es rígida. Nuestra naturaleza está personificada; y al mismo tiempo, no existen personas sin una naturaleza. seve unificada en su persona ${ }^{16}$; (b) La persona humana es libre, aunque no totalmente. Sus decisiones están condicionadas por el conocimiento que posee, por las circunstancias, por sus emociones, etc.; (c) La persona humana es capaz de crecer o perfeccionarse (aprendizaje positivo) y de estropearse (aprendizaje negativo); y (d) La persona humana es un ser dependiente o contingente, no solo del entorno inanimado sino -sobre todo-de las personas con las que interactúa.

\section{Modelo de Pérez López}

El profesor Pérez López, al igual que Melé y González Cantón (2015: 20), decía que el estudio científico del funcionamiento de las organizaciones debía partir de una antropología que no fuese una abstracción incompleta, como pasa en el caso del homo economicus o los presupuestos positivistas; es decir, que no separe lo que en principio está unido: la acción de la persona. Para lo cual, era evidente que el estudio de la acción de las organizaciones (entre ellas las económicas) debía ser analizado mediante la explicación de las acciones de las personas que componen las organizaciones. Y, a su vez, el análisis de la realización de una acción concreta debía ser realizado medianteaquello que es su causa, o aquello que la explica, es decir, las decisiones personales (Pérez López, 1991: 19).

Las decisiones determinan las acciones concretas que realizan las personas, y es esta la suma de acciones la

16 Nótese que, a su vez, la única manera de integrar la ética en la toma de decisiones es tomando en cuenta esta premisa: no hay acciones empresariales y éticas, hay acciones con resultados económicos y éticos ( $\mathrm{y}$ otros). 
que constituye la acción conjunta de la organización formada por esas personas. La naturaleza de una organización especifica el conjunto de acciones posibles de esa organización, del mismo modo que la naturaleza de las personas especifica el número de acciones posibles para esas personas. La acción real ejecutada por una persona en un momento determinado ha de pertenecer siempre al conjunto formado por todas aquellas acciones que, a dicha persona, le es posible realizar. Pero cual sea esa acción en concreto depende de la decisión que tome esa persona (Pérez López, 1991: 19).

De esta forma, la antropología de Pérez López es una antropología de la acción y decisión humana que integra, bajo el supuesto que la acción es una sola, los diferentes resultados que esta pueda tener (económicos, éticos, etc.). ¿En qué se diferencia esta antropología de una antropología filosófica? En primer lugar, en que no es filosófica, sino que es un modelo científico que puede dar ciertos criterios universales para la toma de decisiones real y no solo el análisis especulativo de esta; además de poder sostenerse en diferentes visiones del ser humano (diferentes filosofías del hombre). Sin embargo, dada la posibilidad de confusión (que el mismo Pérez López previó, dado el paradigma positivista), aclararemos este punto.

\subsection{Antropología analítica y antropología filosófica}

Como mencionamos, la ética y las decisiones empresariales pueden ser unificadas mediante una antropología que llamaremos analítica, término con el que Pérez López (1995) a veces designaba a su teoría. Su objeto formal o método es distinto de la antropología filosófica y conviene no confundirlas ${ }^{17}$. El objeto de la antropología analítica es más abstracto ${ }^{18}$, en el sentido que aísla ciertos aspectos de la realidad estudiada (el hombre y su actuar libre), para considerarlos más atentamente, desinteresándose de los demás. Es, al fin y al cabo, parcial, con tendencia al esquematismo, es decir, es un modelo; en cambio, la antropología filosófica es total, en cuanto va a lo esencial (Sanguineti, 2007: 178) ${ }^{19}$.

Ahora bien, el objeto de estudio de la antropología analítica es el ser humano en cuanto a su acción (lo cual presupone una naturaleza humana), centrándose en sus acciones con otros seres humanos (las interacciones que sostiene). Se estudia ese tipo de interacciones -aunque prescindiendo de la naturaleza concreta de la persona-, tomando como objeto formal el análisis de la acción humana desde un modelo con base en la teoría de

«Antropologías distintas no implica que sean contradictorias ni incompatibles. Una antropología analítica transmite siempre de manera implícita una antropología filosófica, de la misma manera que la física experimental lleva implícita una filosofía de la naturaleza» (Alcázar, 2010: 64)

18 Es abstracto, pero no incompleto.

19 Cabe mencionar que la distinción entre filosofía y ciencias no siempre es rígida; pues hay cuestiones en donde los modelos propuestos por las distintas antropologíasvan tomandociertocarizfilosófico, sobre todo en lo que respecta al comportamiento racional y libre del ser humano (que es el objeto, en parte, de la antropología analítica); a su vez, la filosofía, cuando se aplica a determinados sectores de la realidad, se aproxima o otras ciencias (Sanguineti, 2007: 179). 
sistemas ${ }^{20}$. Utilizando para la descripción del actuar humano conceptos como "agente", "sistema", "regla de decisión", "aprendizaje",

"eficacia", etc.

Un esquema básico de la antropología analítica de Pérez López puede ser el que se presenta en la Tabla 1 (sin ánimo de ser exhaustivo), haciendo un paralelismo con el de la antropología filosófica'a

Tabla 1

Antropología Filosófica y Antropología Analítica

\begin{tabular}{|c|c|c|c|c|c|}
\hline \multicolumn{3}{|c|}{ ANTROPOLOGÍA FILOSÓFICA } & \multicolumn{2}{c|}{ ANTROPOLOGÍA ANALÍTICA } \\
\hline $\begin{array}{c}\text { Naturaleza } \\
\text { humana }\end{array}$ & $\begin{array}{c}\text { Necesidades } \\
\text { Humanas }\end{array}$ & Perfeccionamiento & $\begin{array}{c}\text { Resultados de la } \\
\text { acción }\end{array}$ & $\begin{array}{c}\text { Motivos de la } \\
\text { acción }\end{array}$ & $\begin{array}{c}\text { Criterios de } \\
\text { decisión }\end{array}$ \\
\hline $\begin{array}{c}\text { Corporeidad - } \\
\text { Psiquismo }\end{array}$ & Materiales & $\begin{array}{c}\text { Salud corporaly } \\
\text { mental }\end{array}$ & Extrínsecos & Extrínsecos & Eficacia \\
\hline $\begin{array}{c}\text { Inteligencia } \\
\text { Voluntad }\end{array}$ & Afectivas & Virtud Moral & Trascendentes & Trascendentes & Consistencia \\
\hline
\end{tabular}

Nota: Adaptado de "Las Decisiones Directivas: Una aproximación antropológica al logro de eficacia y de aprendizajes positivos en las organizaciones" de Alcázar, 2010: 102.

20 Estudia al ser humano (objeto material), en cuanto a su acción (objeto formal quod) y a la luz de la teoría de sistemas (objeto formal quo), Cfr. (Sanguineti, 2007: 173)

21 El ejemplo es tomado de la tradición filosófica aristotélico-tomista. 
Conviene señalar entonces, de antemano, que la antropología analítica de Pérez López armoniza con una antropología filosófica que incluya los supuestos filosóficos antes mencionados ${ }^{22}$ : la unidad de la acción, la libertad, el aprendizaje (positivo y negativo) y la contingencia (o necesidad de un entorno). Haciendo esto, buscamos hacer explícitos los supuestos filosóficos subyacentes al modelo perezlopiano, aceptando de antemano las consecuencias lógicas que se sigan de dichos supuestos ${ }^{23}$.

Pérez López se sirvió de los desarrollos de la teoría de sistemas de William Ross Ashby, uno de los pioneros de la cibernética. Aunque los modelos de Ashby parecen ya superados (Alcázar, 2010: 66), nos basaremos en sus propuestas, junto con las de Von Bertalanffy (2004), el padre de la teoría de sistemas, y las del propio Pérez López para exponer la antropología analítica.

\subsection{La antropología analítica}

Teniendo en cuenta la premisa de que la acción es una y que la persona humana es contingente (requiere de un entorno), podemos tomar la teoría de sistemas y decir lo siguiente: un sistema (al que

22 La antropología analítica es compatible con distintas filosofías del hombre. Por ejemplo, con antropologías de cuño Aristotélico, Tomista, Poliano, Wojtyliano, antropologías personalistas (como la de Buber o Nedoncelle) entre otras. Para simplificar este ensayo, tomaremos como base la antropología aristotélico-tomista del ejemplo.

23 Es importante notar que es aquí donde entra el debate filosófico, que no es el objeto de este ensayo. llamaremos agente), presenta un problema de acción (ha salido de su estado de equilibrio y busca volver a él, o busca un estado de equilibrio mejor), y realiza una acción en un entorno que le permitirá resolver el problema. Esto puede ser graficado de la siguiente forma:

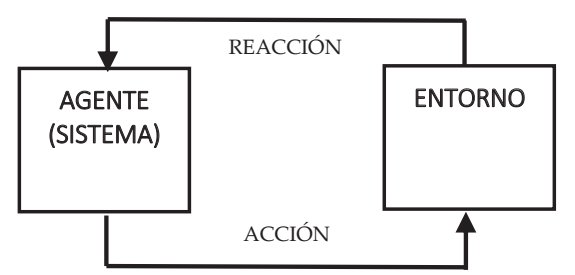

Figura 1. Modelo básico de sistema. Original de Teoría de la acción en las organizaciones: la acción personal de Pérez López, J.A., 1991, p.25.

La figura 1 es el modelo básico para cualquier acción de cualquier agente que requiera de un entorno para resolver sus problemas $^{24}$. Se puede identificar al menos

24 Sobre agentes que requieran actuar con un entorno para satisfacer sus problemas, téngase en cuenta lo que dice Vélaz (1996: 261) «(...) conviene aclarar el concepto de acción humana. (...) la acción en realidad es "inter-acción”, es decir, un proceso de intercambio con el entorno, mediante el cual el ser humano trata de mejorar con su intervención una situación que considera problemática». Además, los sistemas no se “autorregulan", es decir, no vuelven de manera autónoma a la situación de equilibrio (requieren de un entorno, de otros agentes) para ser "felices". Es evidente que esto es lo que suele pasar con las distintas naturalezas que pueden estar representadas por la noción de sistema. Por ejemplo: una persona adquiere una enfermedad, necesita de medicinas que lo vuelvan a su estado de 
cuatro variables explícitas: (a) el agente o sistema, (b) la acción llevada a cabo por el agente (y la acción del entorno o reacción); (c) el entorno con el que el sistema se relaciona e, implícitamente, (d) el problema en cuestión.

\subsubsection{Noción de sistema (a y c):}

Un sistema ${ }^{25}$ es una entidad que "soporta" una particular relación entre una serie de inputs -entradas o estímulos que recibe del entorno- y una serie de outputs acción de respuesta, salida del sistema hacia el entorno- (Pérez López, 1974c: 1), al cual llamamos agente. Este modo de ver al agente prescinde de la naturaleza concreta de las entidades en cuestión. Esto se debe a que no es necesario conocer todos los elementos de la interacción dentro del agente en cuestión (pudiendo quedar implícitos). Además, el "entorno" (c) con el que el agente se relaciona es un sistema o agente. Dependiendo del

equilibrio (salud o felicidad). A veces se suele decir que "una gripe se pasa sola”, sin embargo, siendo totalmente estrictos, esto no es así. El sistema sigue estando siempre en relación a un entorno -la gripe "se pasa sola" si es que el medio ambiente, o "entorno", en el que se encuentra la persona es favorable para dicha curación-. Desde un punto de vista filosófico, podemos decir que solo un ser es absolutamente independiente, el Ipsum Esse Subsistens (Dios); lo cual mostraría que todo ser es dependiente, de una forma u otra, de otro para resolver sus "problemas".

Introducida por Ludwig von Bertalanffy (1950). Ver Hatch, 1997: Organization theory (modern, symbolic and postmodern perspectives). New York: Oxford University Press, pp. 34-41. Cita tomada de (Alcázar, 2010: 67) tipo de "entorno" con el que el agente interactúe, las acciones que deba realizar pueden variar.

El sistema o agente (tanto activo como reactivo -entorno-), tal como se presenta en la figura 1, corresponde a un tipo de sistema muy simple (mecánico o estable), debido a que en la interacción no aprenden, es decir, no se modifican los elementos internos con los cuales decide el agente. Pero ¿qué pasaría si el sistema se modifica?, es decir, ¿qué sucede si aprende? Esto modificaría la interacción, la cual representamos en la figura 2.

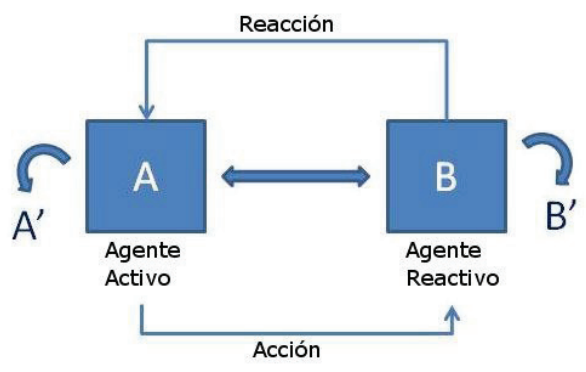

Figura 2. Agentes, interacción y aprendizajes. Original de Fundamentos de la Dirección de Empresas de Pérez López, 2006: 53 .

Donde el agente activo (A) tiene un problema que lo lleva a realizar una "Acción" para intentar solucionar el problema; para hacerlo requiere de un entorno (B) donde pueda obtener una "Reacción" que sea la solución de su problema. En este caso, se toma a priori que dicho entorno es el más complejo posible (es decir, es también un sistema que aprende), para evitar no tomar en cuenta variables que puedan ser relevantes en la resolución del problema. Por último, tenemos los posibles aprendizajes 
(sean positivos o negativos) que puedan presentarse en los distintos agentes de la interacción (A’ y B'). Una vez que el agente A interactúa con el agente $B$ y ocurre que $A$ ha aprendido y ahora es A' [A + Aprendizaje de $\left.A=A^{\prime}\right]$, la interacción no es la misma, ahora es del sistema A' con B. Lo mismo sucederá si B aprende, o si ambos aprenden (caso más complejo).

¿A qué nos referimos con aprender? Aquí no vamos a entender por aprendizaje la simple incorporación de un contenido o conocimiento, sino un tipo de cambio en la conducta, en el modo de comportarse del agente. Desde el punto de vista de sistemas, es el modo en que el input modifica el sistema de tal forma que se modifican los outputs del mismo (ante el mismo input $\mathrm{u}$ otros inputs). Este cambio en el modo de actuar del agente $u$ aprendizaje del agente podemos entenderlo mejor si entendemos al sistema en términos de «reglas de decisión» que relacionan estímulos y respuestas, de modo que el aprendizaje consiste en un cambio en las reglas de decisión ${ }^{26}$ del agente.

26 «Regla de decisión o regla de transformación -de inputs en outputs-. No es una simple respuesta a un estímulo. Es un cambio en el modo como responde, al mismo estímulo» (Alcázar, 2010: 68). El “complejo de elementos en interacción”, es decir, la relación entré inputs y outputs, es a lo que nos referimos como "reglas de decisión”, sean las que estas sean. Recuérdese que continuamos en un grado de abstracción formal que deja de lado la naturaleza concreta del ente en cuestión.
Siguiendo a Pérez López, podemos definir el aprendizaje de la siguiente forma:

Entenderemos por aprendizaje cualquier cambio que ocurra en los agentes como consecuencia de la ejecución del proceso de interacción, siempre que dicho cambio sea significativo para la explicación de las futuras interacciones. (...). $\mathrm{Si}$ denominamos regla de decisión al conjunto de operaciones -cualesquiera que estas puedan ser- por las que un agente activo elige su acción (o agente reactivo su reacción), el aprendizaje es el concepto que utilizaremos para recoger los cambios en las respectivas reglas de decisión, cambios que han sido provocados por la interacción ${ }^{27}$ (Pérez López, 1991: 28).

El carácter distintivo del modelo de Pérez López frente a los de sus predecesores es el énfasis en el aprendizaje como criterio de clasificación de sistemas. Así, podemos tener una clasificación de sistemas como la que sigue ${ }^{28}$ :

1. Sistemas mecánicos o estables («stable systems»): no aprenden en el sentido en que aquí nos referimos a aprender. Cuando actúan no se altera el modo

27 Cursivas nuestras.

28 Una clasificación más detallada puede encontrarse en Alcázar (2010: 71-77). Los términos en inglés son utilizados por Pérez López en sus originales en inglés de 1974. Ver (Pérez López ,1974a), (1974b) y (1974c). 
de funcionar del sistema. La experiencia no deja huella en el modo como deciden.

2. Sistemas ultraestables («ultraestable systems», «Homeostatic systems» o «simple adaptive systems»): son aquellos cuyo funcionamiento mejora como consecuencia de su acción ${ }^{29}$. Aprenden y su aprendizaje es siempre positivo: cada vez toman mejores decisiones, cada vez enfrentan mejor los problemas con los que se encuentran.

3. Sistemas libremente adaptables o sistemas libres ("freely-adaptative systems») $)^{30}$ : aprenden, pero a diferencia de los "ultraestables", su aprendizaje puede ser positivo o negativo. $\mathrm{Si}$ el aprendizaje es negativo, cada vez "deciden" peor, es decir, obtienen menos "satisfacción", degeneran en situaciones de "orden" menor y, en el

29 "Mejora" significa resolver su problema, vuelve a su estado de equilibrio o consigue uno mejor, es más «feliz», cfr. "noción de problema”.

30 Pareciera que lo introduce Pérez López en 1974, fruto de su investigación doctoral: se doctoró en HBS en 1970. Y su tesis doctoral es recogida en Anthropology and sociology: A cybernetical approach (1974C). Rosanas (2006), destaca este aspecto de Pérez López afirmando que «lo importante en su teoría es el concepto de persona del que se parte y el comportamiento esperable (por supuesto, no en forma "mecánica") de esta persona» (J. Rosanas 2006, 39). Por su parte, Alcázar García, en su investigación doctoral (Alcázar, 2010: 75) menciona no haber encontrado el concepto en otros autores. límite, desaparecen. Este sería el modo de serde la persona ${ }^{31}$, el agente personal ${ }^{32}$.

Teniendo esto en cuenta, desde la antropología analítica, el análisis de una acción debe tener en cuenta el tipo de agente más complejo, es decir, que tanto el agente activo como el reactivo sean considerados sistemas libremente adaptables ${ }^{33}$. Las razones

31 Como dice Llano (2008: 27-28): «Con todas mis limitaciones soy como un avanzadísimo ingenio cibernético: aprendo de mis aciertosy de mis errores. Cuandoaprecio mis aciertos, refuerzo esa línea de conducta y la enriquezco con el registro de los nuevos casos, diversificando así las posibilidades de acción. Cuando detecto mis errores, retroalimento las posiciones de partida, atemperando las actitudes que han conducido a los diversos fallos, y potenciando aquellas que puedan neutralizarlas y sustituirlas. (...) Pero en mi actividad acontece también el aprendizaje negativo, en el que desgraciadamente ya no se registra esa versatilidad del autogobierno. Baste pensar en fenómenos como la envidia, el engreimiento o el rencor, que no me son desconocidos. El más temible de todos ellos es el resentimiento, porque me puede paralizar durante mucho tiempo. (...) El pasado comienza a ser un fardo insoportable que amenaza con dominar mi vida entera. Me percato de que se agota mi capacidad de rectificación. Incomprensiblemente, pero de modo muy real, empiezo a hacerme daño a mí mismo. Si insistiera en esta trayectoria, sería el comienzo de la vida malograda».

32 Se destaca nuevamente que esto no es la naturaleza de la persona humana desde la filosofía. Es su modo de ser visto desde una perspectiva de teoría de sistemas, siendo siempre parcial y abstracta (en el sentido de que no se analiza las causas últimas), pero no necesariamente incompleta (pues toma en cuenta -desde el punto de vista de la acción- todas las variables).

33 Esto se debe a que, salvo en situaciones muy simples, para resolver un problema una persona 
son eminentemente epistemológicas: el sistema estable es un caso particular del sistema ultraestable que es un caso más general, es decir, es la situación en la cual el aprendizaje del sistema ultraestable es cero ${ }^{34}$; de la misma forma, el sistema ultraestable es un caso particular de un caso más general que es el del sistema libremente adaptable, es decir, la situación en la cual el aprendizaje negativo del sistema libre es cero y existe aprendizaje positivo. De esta forma, el caso más general es el del sistema libremente adaptable, que incluye a los otros dos. ¿Por qué razón considerar tanto al agente activo como al reactivo como sistemas libres?, porque, de elegir otro, se estaría «excluyendo positivamente la posibilidad de conceptualizar» aquellos dinamismos que presentan los otros dos tipos; es decir, sería una abstracción incompleta 35 (Pérez López, 1991: 45-46).

Para Pérez López, sería una abstracción incompleta aquel modelo teórico que no

necesitará de la colaboración de otras personas (Ariño, 2005: 19). Como dice Vélaz (1996: 261) «(...) lo verdaderamente interesante del entorno son las personas que lo componen, por cuanto lo que nos importa es medir cómo les influyen las acciones de los demás y cómo reaccionan ante ellas. Tal influencia será relevante solo si repercute en su manera de comportarse, esto es, si introduce cambios capaces de modificar sus reacciones futuras. Si eso ocurre, decimos que las personas aprenden a actuar de cara a nuevas decisiones, tanto quien ha tomado la iniciativa como las que forman el entorno humano.»

34 Un sistema "ultraestable" puesto en condiciones que impiden su aprendizaje, podría, con esa condición, ser considerado estable.

Veremos esto con más detalle más adelante. tome en cuenta todas las consecuencias completas de las decisiones del agente, es decir, que no le permita "evaluar" integralmente su acción individual (Ferreiro, 1997, 14). De tal forma que, si el agente no toma en cuenta todas las consecuencias de sus acciones, debido a diversos paradigmas implícitos en su forma de decidir, este no llegará a su situación de equilibrio (satisfacción o felicidad), a no ser por aspectos ajenos al agente y la interacción (en otras palabras: suerte). Ahora bien, si el agente realmente busca su satisfacción (estado de equilibrio) y que, para alcanzarlo requiere varias interacciones con diferentes entornos; entonces, si asume un modelo de toma de decisiones que no tome en cuenta todas las posibles variables, podría implicar un aprendizaje negativo (el propio modelo es insuficiente); y, por otra parte, si considera todas las variables (abstracción completa) se podría procurar un aprendizaje positivo. De esta forma, la satisfacción del sistema, estado de equilibrio buscado o «felicidad» depende de la toma de decisiones, que a su vez depende de las variables que se tomen en cuenta según el tipo de sistema considerado. Como dice Pérez López (1991: 48):

En definitiva, parece mejor arriesgarse a ser cómico -utilizando las categorías de los sistemas libremente adaptables (...) (que incluyen la posibilidad de aprendizaje negativo)- que correr el riesgo de provocar una auténtica tragedia, utilizando las categorías de los sistemas estables (que excluyen cualquier tipo de aprendizaje) para intentar, sin poder conseguirlo, hacer ciencia sobre el ser humano (paréntesis nuestros). 
Nótese que una abstracción incompleta impedirá analizar todas las variables detrás de una acción (todos los criterios de decisión), lo cual desembocaría nuevamente en la "tesis de la separación", donde las acciones éticas no están integradas con las acciones económicas en una sola acción.

\subsubsection{Noción de problema (d):}

Se tiene un "problema" cuando existe una situación que saca del equilibrio al agente o sistema. Pérez López (1991: 25) lo define de esta forma: «En general, se entiende por "problema" la existencia de una situación que no es del todo agradable para una persona», y Ariño (2005: 11) añade «(...) o cuando se sospecha que existen situaciones más agradables que las actuales». Ahora bien, dicho problema depende de la interacción con un entorno, con lo cual podríamos definir el "problema de acción" como «el deseo de un agente activo, de conseguir una cierta satisfacción, satisfacción que depende de que se produzca una cierta interacción con un agente reactivo (entorno)» (paréntesis nuestros) (Pérez López, 1991:31). Nótese que el problema, es decir, la situación "mala", es formalmente mala, sin contenido material o real (alguna naturaleza concreta) de lo que representa dicha "maldad". Lo mismo podemos decir de la situación de equilibrio, satisfacción o felicidad del agente. Por "solución del problema" suele entenderse la aplicación de una acción que transforme esa situación de modo que tal agente encuentre la satisfacción o estado de equilibrio perdido (felicidad) (Pérez López, 1991: 25). Así, «resolver el problema es poner en práctica una decisión que hace que desaparezca la situación desagradable o que permita acceder a una situación más agradable» (Ariño, 2005: 11).

\subsubsection{Análisis de la acción humana (b)}

El modelo básico para realizar un análisis de la acción humana puede graficarse tal como se muestra en la Figura 2, considerando a ambos agentes como sistemas libremente adaptables, es decir, capaces de aprendizaje positivo y negativo. Desde aquí puede atenderse al hecho de que cuando una persona realiza una acción interactuando con otra persona, esa acción puede presentar tres resultados distintos e irreductibles entre sí que se corresponden a tres tipos de motivos diferentes (Pérez López, 2006: 54). Al realizar esto, se busca entender todos los posibles resultados que se dan en una interacción y así poder realizar una abstracción completa de la acción y decisión humana ${ }^{36}$.

\subsubsection{Resultados de la acción:}

a) Tipo 1 (Resultado extrínseco): $\mathrm{La}$ Reacción (R) es el resultado de la interacción (Acción - Reacción) entre los dos agentes (las dos personas) ${ }^{37}$.

36 Nos basaremos sobre todo en la exposición de Ferreiro y Alcázar (2012) y Alcázar (2010). La principal obra de Pérez López que toca el tema de lleno es «Fundamentos de la dirección de empresas» (2006) a la que nos remitimos como fuente primaria. No abordaremos los desarrollos de la obra «Teoría de la acción humana» (1991), pues esta última desarrolla con mayor detalle y rigor los procesos internos de un sistema libre, lo cual escapa a los objetivos de este ensayo.

37 Utilizaremos "agente" o "persona" de forma intercambiable. Nos estamos refiriendo al tipo de sistema libremente adaptable. 
Resultado externo a la persona que actúa. Depende de la respuesta de otro (B).

b) Tipo 2 (Resultado Intrínseco): Es lo que le ocurre a la persona que realiza esa acción. Cambia del estado «A»a «A'». Este cambio es un aprendizaje: resultado interno en la persona que actúa $^{38}$. Este aprendizaje depende solamente del hecho de realizar la acción, con la independencia de la respuesta del otro (B).

c) Tipo 3 (Resultado trascendente): Es lo que le sucede a la persona con la que se interactúa. La otra persona cambia de un estado «B» $\mathrm{a}$ «B'» $\left[\mathrm{B}^{\prime}=\mathrm{B}\right.$ + Aprendizaje de B]. Resultado externo al que actúa.

Ejemplo: Pensemos en Juan, un practicante de medicina. Cuando interactúa con Pedro, un paciente enfermo, se obtendrán los tres resultados mencionados. Tipo 1: la contraprestación por la acción de curar. Juan, al brindar el servicio médico a Pedro, este le paga por sus servicios. Tipo 2: el estado en que queda Juan. Juan ha ganado experiencia por haber curado a Pedro, ahora es un mejor médico y está en mejores circunstancias de curar el tipo de enfermedad que tuvo Pedro (si el aprendizaje fue positivo) y que, por tanto, desde su punto de vista, puedan generarse mayores

38 Este aprendizaje puede ser positivo o negativo. En los sistemas ultraestables este cambio sería solo positivo y en los estables no habría cambio alguno. interacciones de éxito con otras personas (es decir, que le paguen por sus servicios y resuelva sus problemas resultados del tipo 1). Tipo 3: El estado en que queda Pedro. El aprendizaje de Pedro puede ser diverso, puede haber aprendido la causa de su enfermedad y saber prevenirla, aprender que tipo de medicamentos debe de tomar si vuelve a enfermarse, aprender cuales son los síntomas de la enfermedad que padeció, aprender que Juan es un buen médico (competente) y que puede curarlo, aprender que Juan es confiable, cobra lo justo y busca que se cure, etc.

Es importante notar que, en cada interacción, siempre se dan los tres resultados juntos ${ }^{39}$ : R, A' y B'. Independientemente de cuál sea la intención ${ }^{40}$ de la persona que actúa. Además, con cada interacción cambia la relación entre las personas como consecuencia de los cambios que se producen en uno y otro (Alcázar García 2010, 107). Esta relación está graficada en la Figura 2 como la flecha intermedia que "unifica" a ambos agentes y es lo que entendemos aquí por

39 Considerando que ambos son sistemas libremente adaptables. Dado que el hombre es el caso más complejo que conocemos, utilizamos este tipo de sistema. Podría utilizarse otros sistemas para otros casos, siempre que se esté completamente seguro de que son sistemas estables o ultraestables (en el caso de, por ejemplo, materia inorgánica).

40 La intención es el motivo principal -de una combinación de motivos usualmente- que busca el agente. 
organización ${ }^{41}$ (en el caso de una empresa, puede ser con los trabajadores o con los clientes). Con cada interacción, los resultados del tipo 2 y 3 terminan modificando la relación entre los dos agentes, es decir, alterando la calidad de la organización: la mejora o empeora. Esto se debe a que ya no existe la interacción entre $\mathrm{A}$ y $\mathrm{B}$, pues el cambio de «A» en "A'» produce la relación $A^{\prime}$ y $B$ (si es que los cambios en B fueron irrelevantes).

\section{3·3.3.2.Motivos de la acción ${ }^{42}$}

La acción tiene distintos tipos de resultados o consecuencias, los cuales «pueden constituir una poderosa fuente de motivación, es decir, pueden ser directamente buscados por la persona que actúa y ser, en consecuencia, motivos para que realice la acción» (Pérez López 2006, 52). Los motivos son las razones por las que un individuo quiere y decide libremente elegir una acción ${ }^{43}$, y están representadas formalmente por los tres tipos de resultados que puede conseguir con su acción. Estos resultados representan la realidad misma valorada según la naturaleza

41 «Una organización humana es un conjunto de personas cuyos esfuerzos -cuyas acciones- se coordinan para conseguir un cierto resultado $\mathrm{u}$ objetivo que interesa a todas ellas, aunque su interés pueda deberse a motivos muy diferentes». (Pérez López, 2006:14)

42 No abordaremos el análisis de la motivación humana, que es distinto de los motivos de la acción. Esta distinción la abordan otros autores de manera sintética (Cfr.Ferreiro y Alcázar, 2012 \& Ariño, 2005).

43 Recuérdese el otro supuesto: la persona humana es libre, pero no completamente. real del individuo; es decir, según las necesidades de las personas ${ }^{44}$.

Teniendo esto en cuenta, podemos decir que la intención es el motivo principal, o la combinación de motivos, que busca el que actúa. «Todos sabemos -dice Alcázar García (2010, 108) -, por experiencia propia, que cuando realizamos una acción no siempre la realizamos con la misma intención, buscando el mismo motivo (objetivo o resultado)»(cursivas nuestras). Puede que existan infinidad de motivos, pero todos ellos pueden reducirse siempre a los tres tipos de resultados que hemos señalado anteriormente. Los tres pueden ser motivos para actuar, por lo tanto, existen tres tipos de motivos.

Es importante notar que distintas personas pueden estar realizando la misma acción buscando motivos diferentes. Esto se debe a que cuando observamos el comportamiento de una persona, lo único que podemos apreciar es el aspecto externo de la acción que realiza, no podemos percibir directamente el motivo que dicha persona busca al actuar, es decir, su intención. El mismo agente puede realizar la misma acción unas veces con una intención y otras con otra diferente (Cfr. Alcázar, 2010: 109). Como anota Alcázar:

Es vital darse cuenta de esto, para evitar realizar interpretaciones poco realistas a la hora de entender la acción de los demás (...). Tanto el aspecto externo (lo que los demás pueden apreciar)

44 Que pueden ser materiales, cognoscitivas y afectivas. Ver Figura 1: Antropología Filosófica y Antropología Analítica. Estas necesidades las propone el mismo Pérez López (2006: 58-6o). 
como la intención con que se hace, califican de modo completo la acción que una persona realiza (...). Esto tiene mucha importancia al evaluar el comportamiento de otras personas: ha de hacerse en base a la intención con que lo hace (y esto no es directamente observable como tampoco su estado interior) y no solamente tomando en cuenta lo que hace (Alcázar, 2010: 109).

Tomando todo esto en cuenta, decíamos que a los tres tipos de resultados le corresponden tres tipos de motivos.

a) Motivos extrínsecos (tipo 1): "Corresponden a los resultados extrínsecos de la acción y son aquellos con los cuales se satisfacen las necesidades psico-corpóreas. (...) La persona “tiene más” o se deshace de algo que lo molesta» (Ferreiro y Alcázar, 2012: 60).

b) Motivos intrínsecos (tipo 2): Corresponden a los resultados intrínsecos. Se busca «lo que le sucede a la persona por realizar la acción» (Ferreiro y Alcázar, 2012: 61). Este cambio interno buscado, que se produce en quien actúa, es un aprendizaje que puede adoptar dos modalidades, dependiendo del tipo de resultado que se persigue-extrínseco o trascendente- y del tipo de impulso

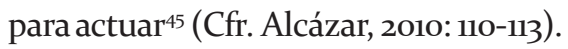

45 Nótese que la búsqueda de motivos intrínsecos (es decir, de aprendizajes o cambios en el agente decisor) tienen la característica de estar íntimamente relacionados con los otros tipos de resultados. El cambio/aprendizaje del agente es una "adaptación" para conseguir el estado de equilibrio/felicidad del agente; pero este depende
Aprendizaje operativo: «Es la adquisición de un conocimiento o habilidad "técnica”. (...) Si es positivo, facilita que las acciones futuras logren mejores resultados del primer tipo; cuando es negativo, aumenta la dificultad para lograr esos resultados en el futuro, en la medida en que su logro dependa solo del que actúa. (...) cuando es positivo, produce satisfacciones en las necesidades cognoscitivas de la persona» (Ferreiro y Alcázar, 2012: 61).

\section{Aprendizaje estructural o evalua-} tivo (autocontrol): Es «el aprendizaje más importante que se da en la persona, se orienta al mejor logro futuro de resultados trascendentes» (cursivas nuestras) (Ferreiro y Alcázar, 2012: 61). Puede ser positivo o negativo. «Cuando es positivo, la persona va teniendo mayor facilidad para lograr resultados trascendentes, de los cuales a su vez depende el logro de los resultados extrínsecos» (Ferreiro y Alcázar, 2012: 62). Produce satisfacciones afectivas.

Los dos aprendizajes son dos tipos de resultados internos que se producen en el agente que actúa por el solo hecho de haber actuado, con independencia de lo que venga del exterior o de lo que les ocurra a las personas con las que interactúa (Cfr. Alcázar, 2010: 112-113).

de lo que recibe (resultados del tipo 1) y de lo que se los otorga (lo que le pasa al entorno o agente reactivo, es decir, resultados del tipo 3 ). Pero, en ambos casos, el motivo es intrínseco: se busca "el cambio interno" que me permita mejores resultados extrínsecos o trascendentes. 
c) Motivostrascendentes(tipo3):Sebusca «el beneficioqueseproduceen otraspersonas comoconsecuencia dela realización de esa acción. Lo que se busca es el servicioa los otros, independientemente del resultado externo de la acción y del grado de satisfacción queel solo hecho de realizarla suponga para elagente» (FerreiroyAlcázar, 2012: 62). Lodeterminantees queel agente activo no busca un cambio o un resultado para sí mismo, sino una mejora en el otro (agente reactivo) ${ }^{46}$.
Cuando se ignora a los demás en la toma de decisiones se prescinde de este tercer tipo de resultados (no existe el motivo que los busque, aunque el resultado se dé). Esta forma de actuar puede producir un aprendizaje estructural negativo que repercutirá - más pronto o más tarde - en la capacidad de obtener no solo satisfacciones afectivas sino también corpóreas, en tanto estas dependan de otras personas (como veremos en el análisis decisional).

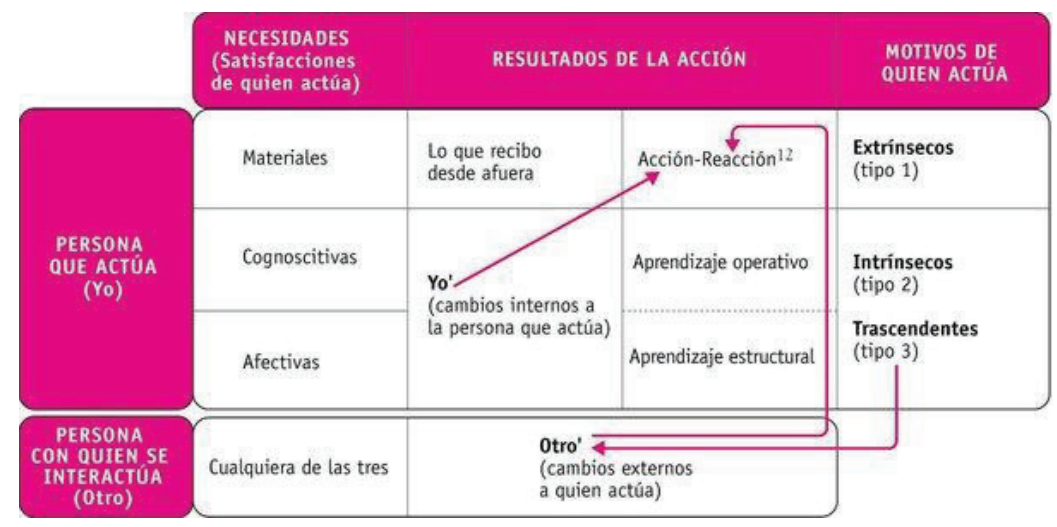

Figura 3. Aprendizajes y Motivos. Original de Gobierno de personas en la empresa de Ferreiro, P. y Alcázar, M., 2012.

46 Estolodiferenciadelabúsquedadeaprendizajesestructurales. Sin embargo, actuar buscando resultados trascendentes-motivostrascedentes-produceaprendizaje estructural (sea positivo o negativo). Para ilustrar la diferencia teórica de ambos, puede tomarse en cuenta quenoes lomismo actuarqueriendo sermejorpersona (querer algo en mí para beneficio de los demás), que actuar para ayudar a los demás sin importar lo que me paseamí(aunquedehechoalgomesuceda-aprendizaje positivo). La diferencia es formal más que real, ya que en ambos casos se busca el bien del otro, aunque en un caso la persona es consciente de que hay resultados intrínsecos (ysonbuscados)yen laotrono. Vistoesto, se puederesumirlosdistintostiposdemotivosyresultados a la manera de la figura 3 .
Es importante recordar que en la mayoría de las acciones intervienen los tres tipos de motivos, aunque con mayor intensidad unos que otros. Ya que todos actuamos por una combinación de los tres tipos de motivos, «de modo que la calidad motivacional viene determinada por el peso que la persona le da a cada uno de ellos» (Alcázar, 2010: 117).

\subsubsection{Criterios de decisión del agente}

Considerando la unidad de la acción y sus posibles consecuencias -resultados-, sean 
económicos, éticos, sociológicos, psicológicos, podemos pasar al análisis de la decisión: los criterios mediante los cuales el agente tomará en cuenta todas las posibles consecuencias de su acción sin caer en una abstracción incompleta. Las razones o motivos por las cuales el agente elige una acción u otra dependen enteramente de él pues es libre. Realizar una acción por un motivo extrínseco (por ejemplo, un resultado económico), no hace que dicha acción carezca de resultados intrínsecos o trascendentes, simplemente no los toma en cuenta en su análisis (ha sido una abstracción incompleta ${ }^{47}$ ). Surge la necesidad del análisis de los resultados de la acción para así obtener una serie de criterios para la toma de decisiones que integren todos los posibles resultados ${ }^{48}$.

47 Esto es precisamente lo que algunos modelos hacen, al pensar que las acciones solo tienen consecuencias económicas y no morales (en base a sus supuestos antropológicos o epistemológicos), construyen un modelo que solo considere dichos resultados.

48 La consideración es formal, teniendo en cuenta los criterios que se darán solamente se asegura que se están tomando todas las consecuencias de la acción. La pregunta sobre ¿cómo realmente estos criterios están integrando la ética en las decisiones? Es una pregunta epistemológica distinta, una pregunta material. Es decir, formalmente se están tomando los resultados éticos (pues están todos los resultados), aunque materialmente debamos acudir al caso concreto para identificar las variables éticas en cuestión. Téngase en cuenta que esta consideración no quiere decir que el mismo modelo no integre cuestiones éticas materiales, de hecho las hace, pero desde sus propios postulados.
Un problema de acción, dijimos, podría definirse como el deseo de parte de un agente activo de conseguir cierta satisfacción, la cual depende de que se produzca una cierta interacción. Dichos problemas se resuelven al ejecutar cualquier acción que, junto con la reacción producida por el agente reactivo, dé lugar a una situación que produzca la satisfacción deseada por el agente activo. Ahora bien, el agente activo elige una acción que resuelva su problema mediante una decisión, la cual es la elección de un plan de acción, por el que se ejecuta una acción con la que se espera lograr una cierta reacción, de tal modo que la interacción resultante produzca la satisfacción deseada. Teniendo en cuenta la Figura 2, podemos decir que un plan de acción para ejecutar una determinada acción (A) que produzca una reacción $(\mathrm{R})$ estaría definido como «Si $(\mathrm{A})$ entonces $(\mathrm{R}) »$, la pregunta sería ¿cómo podemos valorar dicho plan?, es decir, ¿qué criterios tenemos para decir si dicho plan de acción resolverá el problema? Tomando en cuenta los distintos resultados de la acción podemos decir lo siguiente:

\subsubsection{Valoración estática de la decisión de un agente:}

Los planes de acción del agente activo pueden valorarse sin tener en cuenta los aprendizajes producidos de una acción. Así, un plan de acción que es ejecutado por el agente activo supone para este el logro de una satisfacción: aquella que le produce la interacción expresada por el plan [Si (A) entonces (R)]. A ese valor le llamaremos eficacia $^{49}$-valor sintético a priori

49 La eficacia «es el grado de satisfacción logrado por la persona al realizar una acción, el valor 
de un plan de acción para un agente activo-. La eficacia depende de tres valores fundamentales:

- Validez: la acción es válida si la reacción soluciona el problema que se pretende resolver. Es decir, la satisfacción que produce la recepción de la reacción al agente activo ${ }^{50}$.

- Operacionalidad (u Operatividad): la acción es operativa si al agente activo le resulta factible el poder llevar a cabo la reacción. Otra manera de definirla es la del "coste de oportunidad" -el esfuerzo- ligado a la ejecución de esa acción para el agente activo. Se relaciona con la validez en el sentido de que solo es operativo aquello que se prevé satisfactorio (solo quiero hacer una acción si de hecho me satisface) $)^{51}$.

de los resultados externos $(\mathrm{R})$ producidos por la acción, comparado con el esfuerzo desplegado (A)» (Ferreiro y Alcázar, 2012).

50 La validez del plan de acción a priori es solo un supuesto. Es decir, su veracidad (si de hecho el plan de acción produzca la satisfacción buscada) no es un hecho sino un supuesto -depende de que la reacción de hecho resuelva el problema, y esto es solo cognoscible a posteriori, además depende a su vez de la operatividad y de la instrumentalidad. Por prueba y error podremos saber si de hecho era verdad su validez, sin que su desconocimiento descalifique el análisis que aquí se hace (Cfr. Pérez López, 1991: 31-34).

$51 \quad$ Algunas formas de operativizar este criterio las da Alcázar (2015), de la siguiente forma: ¿puedo realizar la acción? ¿se realizar la acción? ¿quiero realizar la acción?, de responder todo afirmativamente, entonces la acción es operativa.
- Instrumentalidad: la acción produce la reacción, es decir, es la operatividad del agente reactivo. La instrumentalidad es aquello que permite que el agente reactivo producir la reacción ${ }^{52}$.

Como dice Pérez López, «la valoración estática de un plan de acción requiere necesariamente la formulación de tres juicios -de tres medidas- que determinen el valor sintético de su plan (su eficacia)» (Pérez López, 1991: 33). Estos tres valores admiten una escala de gradaciones. Así, no será extraño que, en general, un conjunto de planes de acción pueda tener la misma eficacia siendo diferentes la instrumentalidad, operacionalidad y validez. Por ello, dos planes de acción serán idénticos tan solo en el caso de que esos tres valores sean iguales. Estos tres valores son irreducibles, ya que cada uno afecta a una relación distinta de las otras dos, y las tres han de estar necesariamente presentes para que la interacción ocurra. La valoración de solo la validez de una acción sería, en este sentido, una abstracción incompleta, pues no considera todas las variables de forma estática.

52 Tanto la operatividad como la instrumentalidad -en última instancia- dependen de cada persona y de la acción a realizar. Así, si la acción no es operativa, la operatividad depende de la acción y de la capacidad de realizar la acción; siendo el mismo caso para la instrumentalidad. Sí se desea resolver un problema, se puede hacer cambiando la acción para hacerla realizable, o cambiando la capacidad de cada persona para realizar la acción, o una combinación de las variables; pero eso es ya un análisis dinámico. 


\subsubsection{Valoración dinámica de la decisión de un agente}

Tomando tanto al agente activo como al entorno como agentes libres (sistemas libremente adaptables, es decir, personas), se presupone que aprenden (positiva y negativamente). Por otra parte, añadiendo el supuesto de que las interacciones puedan ser recurrentes (interactuemos en diversas ocasiones con el mismo agente para resolver problemas) ${ }^{53}$, podremos tener una abstracción completa, es decir, tomar en cuenta todas las variables para la obtención de satisfacciones. Los criterios dinámicos son:

- Eficiencia: es la operatividad futura del agente activo. Para la persona que actúa, eficiencia es el valor que tienen los resultados internos producidos

Este supuesto es, también, epistemológicamente superior al supuesto de que siempre actuamos con agentes distintos. Consideremos tres razones: $a$ ) de no ser así, el aprendizaje del agente reactivo no tendría importancia, lo cual es un supuesto que, como vimos, es epistemológicamente inferior a suponer que sí tiene importancia; b) suponer que requiero realizar una acción varias veces con el mismo agente abarca más que suponer lo contrario (si tomo en consideración futuras interacciones, se incluye en el análisis la que se está tomando en este momento; la inversa solo considera estas últimas); c) en la realidad, el entorno del que dependemos es recurrente: organizaciones como la familia -el cónyuge es siempre el mismo, los hijos también-, en la empresa -los colaboradores son casi siempre los mismos, los clientes son recurrentes-, con la naturaleza (sistema estable o ultraestable) -la tierra es la misma, nuestra mascota es la misma, etc. por la acción: el paso de «A» « $A$ ' $»$, el aprendizaje. Será tanto más eficiente cuanto más le satisfaga el aprendizaje obtenido (no solo es más fácil la acción para el agente, sino que cada vez le resulta más atractivo el realizarla -más atractivo, entonces más operativo-54). Dicho de otro modo, la acción habrá sido eficiente si la próxima vez que el agente se plantee de nuevo esa acción, su operatividad haya aumentado.

- Consistencia: son los cambios que el aprendizaje produce en el agente reactivo, cambios que determinan la futura instrumentalidad de la acción. Para la persona que realiza la acción, consistencia es el valor -a priori- que tienen los resultados que se producirán en la otra persona: el cambio previsible de «B» a «B'». Una acción es consistente si aumenta la instrumentalidad.

Ahora bien, una evaluación completa es aquella que tome en cuenta todas las posibles consecuencias (resultados de la acción). Esto incluye una evaluación dinámica y no solo estática de los planes de acción. Para tomar en cuenta todos los criterios en la evaluación (eficacia, eficiencia y consistencia), se debe considerar todos los posibles resultados. Esto quiere decir,

54 Se separa la facilidad (aprendizaje operativo) de la satisfacción (que resulte más atractivo la acción), debido a que no necesariamente se dan las dos a la vez. Por ejemplo: en el caso de una persona enferma, puede ser que al tomar una pastilla se sienta mejor, pero se hace cada vez más resistente a la composición química del mismo. Al final, su operatividad es negativa. 
que -para una evaluación completa de la decisión- se debe tener una combinación de todos los motivos al ejecutar una acción ${ }^{55}$. Pero, en especial, se debe de considerar los motivos trascendentes (es decir, siempre tener en consideración los cambios en el otro agente), esto quiere decir considerar el criterio de consistencia. Las razones son epistemológicas y antropológicas: a) la resolución de problemas requiere del entorno, si a este lo consideramos como sistema libremente adaptable y bajo el supuesto de múltiples interacciones, entonces la eficacia presente y futura, depende de que el otro quiera realizar la acción (reacción) que resuelva el problema ${ }^{56}$, dicho de manera sintética: la consistencia es condición de la eficacia futura; b) por otra parte, Pérez López toma en cuenta

55 No solo considerar los motivos trascendentes (que son los más importantes). Si solo se consideran los resultados trascendentes, sin considerar los extrínsecos, no sabremos con exactitud qué es lo que reacción nos ayuda a solucionar los problemas (solo sabremos que la persona con la que interactuamos lo hace posible).

56 Se puede tener en mente una acción válida y operativa; e incluso eficiente; pues todo depende del agente activo, ya que es libre (puede pensar en que le gusta, que puede hacer, etc.); pero no puede influir directamente en el agente reactivo, pues su instrumentalidad depende de él -es libre-. Si simplemente no consideramos los criterios instrumentalidad (dentro de la eficacia) y consistencia, no solo ignoramos lo que no depende del agente activo, sino que nos negamos positivamente a tomar en cuanta alguna forma indirecta de considerar dicha variable (e influir en ella); lo cual, nuevamente, es una abstracción incompleta. que el otro -el agente reactivo- es un yo, es decir, que es persona ${ }^{57}$-razón antropológica-. Cuando se actúa, se actúa sobre todo con personas, lo cual supera el individualismo detrás del homo economicus. «En las organizaciones, como en otros muchos entornos -dice Melé \& González Cantón $(2015,325)$, la acción humana conlleva interacciones con otras personas. Yo actúo, y otro aprende y reacciona a mi acción».

De esta forma, tomando en cuenta todos los criterios de decisión (eficacia -validez, operatividad e instrumentalidad-, eficiencia y consistencia), habremos evaluado totalmente una acción humana, integrando formalmente todas las posibles consecuencias de una acción y, de esa forma, integrando en el modelo cualquier tipo de resultado (sea económico o ético) en la toma de decisiones. Esto debe quedar claro, el modelo de Pérez López es una abstracción, pero es una abstracción completa dados sus supuestos y el análisis que realiza (prescindiendo de la naturaleza concreta del agente); esto quiere decir que, sin importar exactamente el contenido material o real de la decisión, el modelo perezlopiano integra mediante sus criterios a priori las consecuencias éticas y económicas (integra todos los resultados), sean los que estos resulten ser en la realidad. Veamos en el siguiente y último punto un ejemplo que permita ver cómo se Es uno, es libre, puede perfeccionarse o deteriorarse, el contingente, etc. 
da el análisis de una acción, así como el funcionamiento de los criterios.

\subsubsection{Integración de criterios económi- cos y éticos}

La fábula del pastorcillo mentiroso ${ }^{58}$ ilustra muy bien como evaluar una sola acción desde los distintos criterios de decisión; además de mostrar la primacía del criterio de consistencia (y del motivo trascendente)59. Para divertirse un rato -resultado extrínseco u económico-, el pastorcillo avisa a los mozos de su pueblo que viene el lobo y estos acuden apresuradamente en defensa del rebaño. La decisión es operacional e instrumental, y también es válida porque el pastorcillo consigue divertirse a costa de los de su pueblo. Con ello el pastorcillo está aprendiendo que de esa manera consigue divertirse. Conforme esta decisión se va repitiendo, va perdiendo instrumentalidad -el criterio de consistencia no ha sido tomado en cuenta-. La segunda vez quizá todavía los mozos del pueblo acudan en ayuda, posiblemente algunos a regañadientes. A partir de entonces, sin embargo, cuando realmente llegue el lobo no podrá contar con la ayuda de los de su pueblo. Estos, que inicialmente estaban dispuestos a ayudar al pastorcillo, habrán dejado de prestarle atención. La decisión que inicialmente fue eficaz (válida, operativa e instrumental), va perdiendo al ejecutarla su instrumentalidad (es inconsistente). Una decisión que demostró no ser válida, pero al ser instrumental y consistente, permite tener la oportunidad

58 El ejemplo es de Pérez López, citado por Ariño (2005, 30-31).

59 Solo es una primacía del criterio, no que se dejen de lado los demás criterios. de realizar otro intento, otro plan de acción con el mismo agente reactivo.

Este ejemplo muestra cómo, para integrar la ética en una decisión (en este caso, pensar que el otro es persona y no quiere ser engañado), se requiere tomar en cuenta todos los criterios. La decisión del pastorcillo fue inconsistente $y$, por tanto, no ética. Económicamente le fue provechosa en el corto plazo -disfruto de las risas-, pero en el largo plazo tampoco le permitió sostenerse económicamente (la falta de ética afectó a su rendimiento futuro). Por último, de haber considerado el criterio de consistencia (haber tenido un motivo trascendente), habría elegido otra acción económica que le permitiera disfrutar y al mismo tiempo poder mantenerse en el mercado (seguir contando con la confianza de las personas del pueblo).

¿Cómo tomar en cuenta el criterio de consistencia? Al parecer no es un criterio que pueda medirse con modelos matemáticos, sino que es más bien intuitivo. Sin embargo, Pérez López $^{60}$ observa que,

(...) es fácil evaluar la no consistencia de una acción: cualquier persona puede hacerlo. No hace falta más que pensar en lo siguiente: ¿si el otro supiese por qué hago lo que voy a hacer - salvo que fuera tonto -, confiaría en mí? Y si contestamos "no", entonces ese plan de acción es inconsistente. No hace falta más que cambiarse de sitio, simularlo, lo cual es fácil porque yo tengo una información completa sobre

60 Citado por Alcázar García (2010, 127-128), las cursivas son nuestras. 
los motivos que me llevan a aplicar ese plan. Por el contrario, cuando pienso que si el otro conociera mis motivos si confiaría en mí, salvo fuera tonto, entonces mi plan es consistente. A veces hacemos planes inconsistentes, pero nos autoengañamos pensando que el otro no se dará cuenta.

Si se realiza una acción inconsistente se puede deber a dos razones: quien la realiza no se da cuenta de que es inconsistente -error por inadvertencia- o no piensa seguir realizándola.

Cuando se hacen planes inconsistentes a veces se intenta justificarlos explicando que es por el bien de la colectividad, que hay que sacrificarse por el país, etc.; si estas explicaciones no son aceptadas se piensa tal vez que existe un problema de comunicación, cuando en realidad sucede todo lo contrario: estamos comunicando muy bien. Los medios de comunicación podrían llamarse a veces los medios de incomunicación social, pues se utiliza toda la retórica y todos los recursos posibles para convencer al otro de que nuestras intenciones son distintas de lo que son. Comunicar es trasmitir a otra persona, de manera que le sea convincente, algo que yo conozco: algo que es y que yo sé. Comunicar no es utilizar la retórica para convencerlo de lo que yo quiero. ${ }^{61}$

61 Pérez López decía que Aristóteles al analizar los problemas de comunicación en su libro Retórica utiliza calificativos muy duros para esta actitud: dice que esa es la falsa retórica de los sofistas a
Cuando en una acción se dejan de lado los motivos trascendentes, puede suceder que la persona con la que se interactúa, y de cuya respuesta depende mi eficacia, esté cada vez menos motivada para responder de la manera adecuada, pues le resulta menos operativo hacerlo. Si no se tiene en cuenta la consistencia, se podría solucionar un problema inmediato -eficacia ahora-, pero a costa de generar mayores problemas -eficacia futura-: la acción ha sido incorrecta, ha sido una mala decisión.

Buscar de modo exclusivo la eficacia presente puede destruir la eficacia futura, pues implica desatender a los otros dos valores de la acción. Cuando se logra la eficacia de esta manera, se pueden dar las siguientes situaciones (Cfr. Ferreiro \& Alcázar, 2012: 75-76):

- La acción es eficaz, pero es ineficiente: el médico cobró un buen estipendio por curar al paciente (eficacia), pero le ha desagradado la experiencia (ineficiencia) y, por lo tanto, no está dispuesto a repetirla en igualdad de condiciones; se ha perdido operatividad para ese médico.

- La acción es eficaz pero inconsistente: consecuencias peores, el servicio del médico no ha podido curar al paciente (y aun así ha cobrado) o, habiéndolo curado, el trato no le fue agradable. Este no volverá a responder del mismo modo a la misma acción del

los que insulta y les llama hijos de mala madre (Alcázar, 2010, 128). 
médico, pues le resultará menos operativo ir a ese médico. Se ha deteriorado -o destruido- la relación estructural entre el médico y el paciente, y es esa la relación de confianza la que permite la eficacia de la acción del médico en primer lugar.

Visto de esta forma, la condición que permite la eficacia de la acción es la relación estructural o confianza. La calidad motivacional de una persona depende fundamentalmente del peso que los motivos trascedentes tienen en su motivación total. La confianza depende fundamentalmente de que los agentes actúen evitando siempre alternativas de acción inconsistentes, por muy eficaces que resulten. Esta condición de eficacia puesta en la consistencia puede verse desde un mínimo a un máximo. Como mínimo, el decisor debe evitar tomar decisiones inconsistentes sea cual sea la motivación extrínseca que le impulse a tomarla (Ariño, 2005: 33); en el mejor de los casos, se debe buscar ser consistente por motivos trascendentes.

\section{Conclusión}

A estas alturas debe haber quedado claro que el análisis de la acción y decisión humana es necesario para integrar la ética y la economía (entre otras cosas) en la toma de decisiones de los empresarios. Como dijo Ian Mitroff (2004: 187) «las bases filosóficas del mundo empresarial deben ser revisadas en sus fundamentos», es necesario repensar los presupuestos filosóficos en los que se sustenta el management, en busca de una antropología y epistemología que pueda unificar las decisiones éticas de las técnicas, las morales de las económicas. Aquí hemos hecho expuesto uno de esos intentos -el de Pérez López-, basándonos en ciertas premisas filosóficas -sin profundizar en ellas-, centrándonos en la unidad de la acción del decisor. Creemos que es allí donde debe partir el análisis: la acción es una, es cuestión de analizar las consecuencias lógicas necesarias que se siguen de esa primera premisa, estudiando todos los posibles resultados de la acción, sean económicos, éticos, sociológicos, psicológicos, etc. Y, a partir de allí, crear modelos que nos permitan tomar mejores decisiones integrando todos los aspectos de esta, sin caer en abstracciones incompletas. Creemos que, al fundamentar un modelo en un tipo de sistema como el libremente adaptable, se permite analizar la acción en todos sus aspectos y dar todos los criterios necesarios para evaluar cualquier acción tomando en cuenta formalmente todas las posibles consecuencias. Creemos también que esto se resume, en parte, al tomar como criterios de decisión el criterio de eficacia, eficiencia y consistencia; por motivos trascendentes. Ha sido nuestra intención haber dado suficientes razones epistemológicas y antropológicas como para considerar utilizar el modelo de Pérez López en la toma de decisiones. Sin embargo, lo expuesto en este ensayo no es todo lo que el modelo de Pérez López ofrece, esperamos que haya servido también de introducción a su pensamiento con miras a que el lector desee profundizar en él y así poder pasar a la praxis real.

\section{Referencias}

Alcázar García, Manuel. Las decisiones directivas: Una aproximación antropológica 
al logro de efiacia y de aprendizajes positivios en las organizaciones. Pamplona: Pro manuscrito, 2010.

Alcázar, Manolo. Cómo mandar bien. Consejos para ser un buen jefe. Lima: Infobrax, 2015.

Andreu, Rafael, y Josep M. Rosanas. «Manifiesto para un Management mejor. Una visión racional y humanista.» Documento de Investigación DI-885 IESE Business School. Febrero de 2011.

Archer, M.S. «Homo economicus, Homo sociologicus and Homo sentiens.» En Rational Choice Theory, de Margaret S Archer, Jonathan Q Tritter, \& (eds.), 36-56. London: Routledge, 2005.

Argandoña, Antonio. «La dimensión ética de la crisis financiera.» Documento de investigación DI-872. Julio de $2010 a$.

Argandoña, Antonio. Las relaciones entre economía y ética. Barcelona: Dcumento de la División de Investigación del IESE Business School, 1989.

Argandoña, Antonio. «Las virtudes en una teoría de la acción humana.» Documento de la división de investigación del IESE (DI-880) (IESE Business School), Octubre 2010.

Argandoña, Antonio. «Más allá de la eficiencia: Lecciones éticas de la crisis para la cultura empresarial.» Documento de investigación DI-876. Septiembre de $2010 b$.
Ariño, Miguel Angel. Toma de decisiones y gobierno de organizaciones. Barcelona: Deusto, 2005.

Artigas, Mariano. Filosofía de la Ciencia. 2da Edición. Pamplona: EUNSA, 2009.

Chinchilla, Nuria, y Maruja Moragas. Dueños de nuestro destino. Barcelona: Ariel, 2007.

Corcuera García, Justo Paul. Naturaleza del trabajo directivo (una versión moderna de los temas clásicos) y su repercusión en los programas de formación de dirección de empresas. Pamplona: Tesis Doctoral - Pro Manuscrito, 2001.

Drack, Manfred. El enfoque temprano de "sistema" de Ludwin Von Bertalanffy. o5 de 10 de 2016. http://www.gesi. org.ar/articulos/el-enfoque-temprano-de-sistema-de-ludwig-von-bertalanffy/ (último acceso: 23 de 05 de 2017).

Ferreiro, Pablo. «Juan Antonio Pérez López como Científico.» En Acto Académico In memóriam del Profesor Juan Antonio Pérez López, de VV.AA., 104. Barcelona: IESE Universidad de Navarra, 1997.

Ferreiro, Pablo, y Manuel Alcázar. Gobierno de personas en la empresa. 6ta. Lima: Planeta, 2012.

Feser, Edward. Philosophy of mind. Oneworld publications, 2006.

Feser, Edward. Scholastic Metaphysics. A contemporary introduction. Germany: Editions Scholasticae, 2014. 
Feser, Edward. The Last Superstition. Indiana: St. Augustine Press, 2010.

García Cuadrado, J.A. Antropología Filosófica. Una introducción a la Filosofía del Hombre. 6ta Edición. Pamplona: EUNSA, 2014.

Genta, Jordan Bruno. El filósofo y los sofistas. 2da. Buenos Aires: Talleres Gráficos Lumen, 2009.

Ghoshal, Sumantra. «Bad Management Theories Are Destroying Good Management Practices.» Academy of Management Learning \& Education 4, no 1 (2005): 75-91.

González, Wenceslao J. «Racionalidad, historicidad y predicción en Herbert A. Simon.» En Herbert A. Simon: Filósofo de la Ciencia y Economista (1916-2001), de W.J. (ed.) González. Coruña: NETBIBLO, 2003.

Llano, Alejandro. La vida lograda. 6ta. Barcelona: Ariel, 2008.

Lopez Jurado, Marta. La decisión correcta. Barcelona: Desclée De Brouwer, 2010.

Melé, Domènec, y César González Cantón. Fundamentos Antropológicos de la dirección de empresas. Pamplona: EUNSA - Astrolabio, 2015.
Mitroff, Ian I. . «An Open Letter to the deans and the Faculties of American Business Schools.» Journal of Business Ethics 54, no 2 (2004): 185-189.

Nagel, Thomas. Mind and Cosmos. New York: Oxford University Press, 2012.

Pérez López, Juan Antonio. «Anthropology and Sociology.» División de Investigación del IESE, WP. n6, 1974c: 6.

Pérez López, Juan Antonio. «Enseñar a pensar.» En La educación: El reto del tercer milenio, de VV.AA. Barcelona: Institució d'Educació XXV e Aniversari, 1995.

Pérez López, Juan Antonio. Fundamentos de la dirección de empresas. Sexta . Madrid: Rialp, 2006.

Pérez López, Juan Antonio. «Orgaizational control theory: A formal approach.» Docummento de la División de Investigación del IESE, WP. $n^{\circ} 4$, 1974a: 29.

Pérez López, Juan Antonio. «Organizational theory: A cybernetic approach.» Documento de la División de Investigación del IESE, WP. ${ }^{\circ}{ }^{5}$, 1974b: 23.

Pérez López, Juan Antonio. Teoría de la acción en las organizaciones: la acción personal. Madrid: Rialp, 1991. 
Pierpaolo, Donati, y Margaret S. Archer. The Realtional Subject. London: Cambridge University Press, 2015.

Rosanas, Josep. «¿Qué cosas diferentes dijo Juan Antonio Pérez López? .» Revista de Antiguos Alumnos del IESE, 2006: 38-42.

Rosanas, Josep M. «Pero, ¿Qué es el management?» Revista de Antiguos Alumnos. IESE Business School., 2009: 18-22.
Sanguineti, Juan José. Lógica. 7 ma. Pamplona: EUNSA, 2007.

Simon, Herbert A. Administrative Behavior. 4ta. New York: The Free Press, 1997.

Vélaz Rivas, José Ignacio. Motivos y motivación en la empresa. Madrid: Diaz de Santos, 1996.

Von Bertalanffy, Ludwig. Teoría general de sistemas. México: Fondo de Cultra Económica, 2004. 